\title{
Promoção da saúde em doenças transmissíveis - uma investigação entre adolescentes
}

\author{
Health promotion in transmissible diseases - an investigation among teenagers \\ Promoción de la salud en enfermedades transmisibles - una investigación en adolescentes
}

\section{Eveline Pinheiro Beserra', Márcio Flávio Moura de Araújo², Maria Grasiela Teixeira Barroso ${ }^{3}$}

\section{RESUMO}

Objetivo: Relatar uma experiência de promoção da saúde no contexto das doenças transmissíveis com adolescentes. Métodos: Utilizou-se a dialógica freireana: círculo de cultura, constituído por cinco oficinas de Promoção da Saúde com adolescentes da faixa etária de 13 a 16 anos numa escola de Fortaleza-CE. Resultados: Foi identificado que os adolescentes tinham pouco conhecimento sobre os meios de prevenção das doenças transmitíveis (DT) e de sobremodo das doenças sexualmente transmissíveis (DST). Ao final do círculo de cultura, os jovens referiram mudança de comportamento. Conclusão: A prática de educação em saúde orientada pelo círculo de cultura possibilitou apreender aspectos culturais relacionados às DT/DST e dinamizar o processo educativo repercutindo em mudanças de comportamento dos adolescentes sobre a prevenção dessas doenças.

Descritores: Promoção da saúde; Saúde do adolescente; Doenças transmissíveis

\begin{abstract}
Objective: To describe an experience to promote health and prevent transmissible diseases among teenagers. Methods: Freire's dialogue technique, cultural circle, guides the planning and implementation of five health promotion workshops among teenagers aged 13 to 16 years old of an elementary school in Fortaleza- CE. Results: Teenagers lack knowledge of preventative measures of transmissible disease, especially sexually transmissible diseases. After participating in the workshops teenagers reported behavioral changes. Conclusion: Health promotion guided by cultural circle led to better understanding of cultural aspects regarding the prevention of transmissible diseases and sexual transmissible diseases. In addition, cultural circle informed the educational process to promote teenagers' adoption of preventative measures.
\end{abstract}

Keywords: Health promotion; Teen health; Communicable diseases

\section{RESUMEN}

Objetivo: Relatar una experiencia de promoción de la salud con adolescentes, en el contexto de las enfermedades transmisibles. Métodos: Se utilizó la dialógica freireana: círculo de cultura, constituido por cinco talleres de Promoción de la Salud realizado con adolescentes del grupo etáreo de trece a dieciséis años en una escuela de Fortaleza-CE. Resultados: Fue identificado que los adolescentes tenían poco conocimiento sobre los medios de prevención de las infermidades transmisibles (DT), específicamente de las enfermedades sexualmente transmisibles. Al final del círculo de cultura, los jóvenes refirieron cambio de comportamiento. Conclusión: La práctica de educación en salud orientada por el círculo de cultura hizo posible el aprendizaje de aspectos culturales relacionados a lasinfermidades transmisibles/ enfermidades sexualmente transmisibles y dinamizar el proceso educativo repercutiendo en cambios de comportamiento de los adolescentes sobre la prevención de esas enfermedades.

Descriptores: Promoción de la salud; Salud del adolescente; Enfermedades transmisibles

\footnotetext{
1 Acadêmica de Enfermagem da Universidade Federal Ceará- UFCE - Fortaleza (CE), Brasil; Bolsista do PIBIC-CNPq .

2 Acadêmico de Enfermagem da Universidade Federal do Ceará - UFCE - Fortaleza (CE), Brasil,

${ }^{3}$ Livre Docente, Professora Emérita da Universidade Federal do Ceará - UFCE - Fortaleza (CE), Brasil; Pesquisadora do CNPq.
} 


\section{INTRODUÇÃO}

A Promoção da Saúde visa favorecer um estilo de vida mais saudável ao indivíduo, mediante políticas públicas voltadas para diversos campos como a alimentação, moradia, educação, dentre outros, e também pela própria interação do homem com o meio.

Conceitualmente, as doenças transmissíveis podem ser caracterizadas como doenças cujo agente etiológico é vivo e transmissível, podendo a infecção ser veiculada por um vetor, ambiente ou indivíduo. Uma das metas da Saúde Pública é bloquear a ascensão das doenças transmissíveis (DT), já que essas são causas de morbimortalidade mundial, assolando milhares de pessoas, especialmente nos países em desenvolvimento, como o Brasil $^{(1)}$.

A Saúde Pública vem desprendendo uma atenção especial à população jovem, pois essa é mais vulnerável aos riscos à saúde, inclusive as DT e as Doenças Sexualmente Transmissíveis (DST). No que concerne às DST, o cenário agrava-se pelo fato de muitos pais acharem-se despreparados para orientar seus jovens filhos, não conseguindo falar sobre sexualidade nem sobre a prática de sexo seguro, em decorrência de vários fatores, entre eles: a vergonha, a falta de instrução sobre DST e de liberdade com os filhos, o que, em grande parte, podemos atribuir como resultado da cultura na qual eles vivem, em que o sexo ainda é um tabu. Assim, cabe ao profissional de saúde orientar pais e filhos a respeito desse assunto.

A cultura é um ponto importante para o direcionamento da Educação em Saúde, pois o homem independe dela para se manter vivo, mas o modo como realiza suas funções vitais é caracterizado de acordo com o contexto cultural do indivíduo ${ }^{(2)}$. Essa compreensão do cenário cultural é fundamental, haja vista que a cultura é um dos fatores determinantes nos agravos à saúde e no processo de Educação em Saúde.

No Brasil observa-se, por meio de investigações epidemiológicas, que a faixa etária de treze a dezenove anos também está se contaminando, sendo o sexo feminino o mais prevalecente no períosdo de 2001 a $2004^{(3)}$.

A orientação ao jovem sobre a própria sexualidade deve estar inserida na sua realidade e exercida de forma aberta, pois os jovens são imaturos, visto que alguns desejam aventura, e ignoram a possibilidade de se contaminarem com alguma DST, ou até mesmo acreditam que realizam o ato sexual com pessoas seguras, isentas de alguma DT, enquanto na verdade todos estão susceptíveis à contaminação ${ }^{(4)}$. Assim, é importante que o adolescente direcione a sua sexualidade de modo racional, possível de ser questionado, a fim de ter menos riscos à sua saúde ${ }^{(5)}$.
A educação é um compromisso social, é um direito que todos os jovens têm para se tornarem cidadãos capazes de contestar comportamentos inadequados à saúde $^{(\sigma)}$. É importante que haja a realização de ações educativas entre casais adolescentes, permitindo o amadurecimento e o diálogo entre ambos, promovendo o autocuidado a fim de reduzir o receio ou até mesmo a vergonha de abordarem o assunto de sua vida sexual, assim proporcionando a formação de indivíduos comprometidos com sua saúde ${ }^{(7)}$.

As ações educativas frente às DT/DST/AIDS, sobretudo as do enfermeiro, consistem em orientar, retirar as dúvidas e conscientizar o indivíduo para atitudes seguras, que diminuam ou anulem os riscos de contaminação, promovendo, desse modo, hábitos comportamentais mais saudáveis, sendo essa meta conquistada por meio do diálogo e de críticas sobre ações de risco, mostrando que a educação ainda é o melhor meio de prevenção das doenças ${ }^{(8-9)}$.

Nessa perspectiva, o objetivo desse estudo é relatar uma experiência de promoção da saúde no contexto das doenças transmissíveis, intermediada pela dialógica freireana, vivenciada com adolescentes da cidade de Fortaleza-CE.

\section{MÉTODOS}

Movidos pelo interesse de conhecer o contexto cultural dos adolescentes, decidimos realizar círculos de cultura, uma vez que essa metodologia permite que os jovens falem abertamente sobre sua realidade.

O estudo é uma pesquisa-ação ou participante, pois a partir do círculo de cultura, fundamentados na dialógica freireana, desenvolvido sob a forma de oficinas de promoção da saúde, os autores apreenderam aspectos culturais dos jovens relacionados às DT/DST, o que dinamizou o processo educativo visando à mudança de comportamento dos adolescentes sobre a prevenção dessas doenças.

O estudo foi realizado numa escola municipal localizada em um bairro carente da periferia de Fortaleza. Os participantes da pesquisa foram compostos por alunos de uma turma de repetentes da quarta série do Ensino Fundamental, totalizando 28 jovens da faixa etária de treze a dezesseis anos, entre o sexo feminino e masculino, sendo esse o número de participantes de cada oficina de promoção da saúde. A escolha desses participantes ocorreu devido ao fato de percebermos nesse grupo uma carência maior quanto a aspectos educativos do que nas demais turmas da referida escola. A investigação foi desenvolvida de agosto a dezembro de 2005. Os instrumentos e procedimentos utilizados foram a observação, o diário de campo e oficinas de Promoção da Saúde. 
A observação é o método mais adequado para investigar o contexto cultural de um grupo. O observador assume um papel em que sua identidade e os objetivos do estudo são revelados ao grupo pesquisado desde o início. A observação, quando alcança o estádio de observação-participante, obtém como fruto a interação do pesquisador com os participantes ${ }^{(10)}$.

O diário de campo permite o registro detalhado do conteúdo das observações no campo de pesquisa, envolvendo a descrição do ambiente e as reflexões do pesquisador, incluindo suas observações pessoais, especulações, sentimentos, impressões e descobertas durante a fase de coleta de dados.

As oficinas de Promoção da Saúde foram constituídas a partir da abordagem dialógica freireana, círculo de cultura, que permite um aprendizado rápido, contextualizado na realidade dos educandos, existindo uma inter-relação que proporciona liberdade e crítica acerca do assunto abordado nas oficinas, sendo assim um grupo para diálogo, debate e trabalho ${ }^{(11)}$.

O círculo de cultura é composto pelo animador, o qual se caracteriza por organizar e coordenar o grupo, possibilitando a abertura de espaço para a participação dos educandos durantes os diálogos ${ }^{(12)}$. Dessa forma, o círculo de cultura leva à conscientização do grupo, proporcionando a busca de um estilo de vida mais saudável e a mudança de comportamento ${ }^{(13)}$.

O círculo de cultura foi composto de cinco oficinas, com duração média de uma hora e meia cada. As oficinas foram tituladas de forma distinta: $1^{a}$ Oficina - Descoberta das palavras geradoras sobre doenças transmissíveis; $2^{\mathrm{a}}$ Oficina - Parasitoses e cultura dos jovens; $3^{a}$ Oficina Doenças transmissíveis do contexto dos adolescentes; $4^{\mathrm{a}}$ Oficina - Doenças sexualmente transmissíveis e $5^{\text {a }}$ Oficina - Reflexão cultural do aprendizado. As cinco tiveram características relacionadas à Educação em Saúde e o diálogo entre os adolescentes, a partir do seu âmbito cultural.

A pesquisa interligada com a educação pode ser considerada como um instrumento de transformação que possibilita mudança de comportamento a partir de uma reflexão crítica da realidade vivenciada ${ }^{(14)}$.

O estudo obedeceu aos aspectos legais e éticos da pesquisa com seres humanos, tendo sido submetido ao Comitê de Ética do Hospital São José de Doenças Infecciosas e aprovado sob o Parecer No ${ }^{\circ}$ 0053/2004. Vale frisar que o estudo iniciou-se somente após a assinatura dos pais e jovens, do Termo de Consentimento Livre Esclarecido.

\section{RESULTADOS}

Primeira oficina do círculo de cultura - Descoberta das palavras geradoras sobre doenças transmissíveis
Colocamos as cadeiras em semicírculo e iniciamos nosso círculo de cultura, realizando uma dinâmica de grupo para promover a interação dos adolescentes conosco, já que eles não nos conheciam. Após esse momento, nos apresentamos, explicamos nosso propósito de promover a Educação em Saúde e demos espaço para as primeiras palavras geradoras. Essas são ditas pelos próprios participantes do círculo de cultura, que no caso do estudo, são os adolescentes, demonstrando pistas da realidade na qual eles vivem, sendo elas que apontam as regras de como conduzir o círculo de cultura $^{(12)}$.

Após o acolhimento, iniciamos o diálogo, intermediado por uma linguagem acessível para os jovens sobre o conceito de DT, surgindo a palavra geradora AIDS. Geralmente, as pessoas não atentam para as outras formas de contágio de DT, como o ar e água contaminados, insetos, considerando apenas a via de transmissão sexual.

Em seguida, apresentamos todas as formas de contaminação. Então surgiram doenças como: dengue, gripe, sarampo, câncer. Refletindo sobre essas doenças percebemos uma ênfase na citação da Aids e do câncer, que são doenças difundidas e conhecidas em nossa sociedade pelo sofrimento, estresse e preconceitos que elas impõem a suas vítimas. Mesmo que o câncer não seja uma doença transmissível, os jovens a citaram porque, provavelmente, ela está inserida no cotidiano deles.

Durante o diálogo do círculo, surgiram mais palavras geradoras, como hanseníase, catapora, sífilis e calazar, e exemplos de doenças que ascenderam com a modernidade, como diabetes e hipertensão. Surgiu, também erroneamente, o tabagismo como DT.

No segundo momento da oficina, pedíamos para escreverem em um papel qual o conceito deles sobre saúde e o que eles faziam para ter saúde, visto que os conceitos de saúde e doença estão relacionados ao contexto cultural. Os conceitos escritos pelos estudantes permitiram um direcionamento mais pertinente sobre a realidade do grupo ${ }^{15}$. Em relação aos comentários referentes à saúde, muitos disseram que era a ausência de doença, outros, que era ficar próximo de quem gosta e ajudar a quem precisa.

No item intitulado o que fazer para ter saúde, escreveram: não beber água gelada, realizar exercícios físicos, alimentar-se bem, lavar as mãos e não pegar chuva, sendo o item não andar descalço o que prevaleceu entre os demais.

Dois comentários apresentaram-se de forma inusitada: um refere-se ao fato de um adolescente de dezesseis anos ter escrito a afirmação de ter medo de contrair AIDS. Esse fato demonstra a falta de informação sobre a maneira de se prevenir, causando, 
assim, temor nos jovens. E o outro comentário foi a afirmação de um adolescente de 13 anos de que, quando ficasse adulto, não iria beber nem fumar. Esse comentário nos revela o contexto no qual esses jovens vivem, pois se trata de um bairro periférico, violento, onde há muitos desempregados, bares e drogas.

Ao final da oficina, já estávamos com nossas palavras geradoras, demonstrando o contexto cultural dos adolescentes, norteando-nos para a realização das próximas oficinas.

\section{Segunda oficina do círculo de cultura - Parasitoses e cultura dos jovens}

As palavras geradoras apontaram-nos a necessidade de dialogarmos sobre as parasitoses. Trouxemos as fichas de cultura, que têm como objetivo sugerir um debate a partir de figuras de situações da realidade do grupo, levando os educandos a pensar no seu mundo real e criticá-lo ${ }^{(12)}$. Nossas fichas tinham figuras relacionadas ao ciclo parasitário das seguintes parasitoses: amebíase, ascaridíase, giardíase, teníase, cisticercose, ancylostomidíase, larvas migrans, toxoplasmose, doenças de Chagas e leishmaniose tegumentar e visceral.

O diálogo da oficina era voltado para a prevenção dessas doenças. Enfatizávamos métodos corriqueiros para evitar as parasitoses, como lavar as mãos antes de comer e depois de usar o banheiro; não comer carne crua ou mal cozida; lavar bem frutas e verduras cruas; beber água filtrada ou esfriada após a fervura; manter as unhas cortadas e evitar colocar a mão na boca; conservar os alimentos longe de insetos; evitar andar descalço e dar antiparasitários para cães e gatos domésticos, além de higienizar o lar e o ambiente que os cercam.

Durante o diálogo, percebemos uma certa desinformação acerca do assunto e a falta de autocuidado em relação às parasitoses. Os estudantes se mantiveram atentos a parasitas que cães e gatos podem transmitir ao homem, uma vez que animais domésticos estão inseridos fortemente na realidade desses jovens.

Os adolescentes estavam à vontade para relatar contaminações por cisticercose e leishmaniose, tanto tegumentar quanto visceral. Demonstraram estar preocupados desde já em jogarem futebol calçados para evitarem parasitoses de transmissão percutânea.

\section{Terceira oficina do círculo de cultura -Doenças transmissíveis do contexto dos adolescentes}

Norteamos esse encontro como o anterior, a partir das palavras geradoras, e trouxemos as fichas de cultura. Elas continham imagens de lesões das seguintes doenças: dengue, hanseníase, tuberculose e catapora e a forma de contágio dessas doenças ditas anteriormente, acrescentando cólera e hepatite A. Achamos de grande valia abordar essas duas doenças que não foram ditas, haja vista que podem se inserir no âmbito de um bairro periférico.

Durante o diálogo com os jovens sobre a dengue, eles demonstraram ter o conhecimento sobre métodos de prevenção, já que as campanhas de combate à dengue têm apoio dos meios de propagação coletiva. Percebemos os seus conhecimentos nos relatos de prevenção: não se deve deixar água parada, manter a caixa d'água fechada e usar o peixe "Beta" como predador de larvas do mosquito.

Sobre hanseníase, relataram casos de parentes e ficaram atentamente observando as fichas de cultura com a imagem da lesão. Enfatizamos a importância da procura do serviço médico, no caso de identificação de alguma mancha suspeita. Sobre tuberculose, demonstraram a conscientização de que, no caso de tosse e febre por mais de três semanas, devem procurar uma unidade de saúde.

Os jovens encontraram facilidade em dialogar sobre os métodos de prevenção da cólera e hepatite $A$, pois essas doenças estão voltadas para a prática de higiene, assim como as parasitoses. No que diz respeito à catapora, vários deles já haviam tido a doença.

\section{Quarta oficina do círculo de cultura - Doenças sexualmente transmissíveis}

As fichas de cultura traziam imagens de regiões genitais acometidas por lesões das seguintes doenças: sífilis, herpes genital, cancro mole, condiloma acuminado, gonorréia. Outra ficha que trouxemos indicava o método correto do uso do preservativo. Os jovens se mostraram muito interessados em aprender como se prevenir. Preocupamo-nos em explorar cada doença, pois, segundo o relato da educadora da escola, o assunto era algo novo para eles.

Durante o diálogo com o grupo, os adolescentes mantiveram-se concentrados. Somente um jovem relatou ter tido orientação de um profissional de saúde acerca das DST. Outros demonstraram-se envergonhados em participar do diálogo, enquanto outros que permaneciam mais calados nas oficinas anteriores tornaram-se mais ativos nos seus comentários. Diante do desabafo de um jovem na primeira oficina sobre o medo de contrair AIDS, buscamos tranqüilizá-los, tomando como base os métodos de prevenção e o esclarecimento de dúvidas, não somente sobre a AIDS, como também acerca de outras DST.

Poucas perguntas foram realizadas pelos jovens, o que demonstrou que alguns não conheciam o seu corpo, sendo um momento propício à prática de Educação em Saúde. 


\section{Quinta oficina do círculo de cultura - Reflexão cultural do aprendizado}

Essa última oficina foi permeada por um diálogo reflexivo a respeito dos benefícios, ganhos e aprendizado dos educandos após as oficinas. Esse foi um momento de debates. Relataram sobre algumas mudanças de comportamentos, como não deixar água parada, lavar as mãos, não andar descalço, alimentar-se bem, pensar antes de praticar sexo, levar para os encontros preservativos, usar camisinha a fim de evitar as DST/ AIDS e como método anticoncepcional, mas, principalmente, destacaram que dariam mais importância à saúde.

Eles demonstraram, após as oficinas, ter percebido que confere mais valor à saúde buscar hábitos de vida mais saudáveis e métodos de prevenção em relação às DT/DST. Percebemos a compreensão da importância do uso do preservativo, já que ninguém é imune à contaminação de DST/AIDS, e atitudes de higiene como lavar as mãos e o hábito de andar calçado, através de várias colocações sobre meios de promover a saúde.

Por fim, enfatizamos a importância de compartilhar o conhecimento aprendido com outras pessoas do seu vínculo social, pois o círculo de cultura estava direcionado à realidade desses jovens de um bairro periférico. Enfatizando, numa linguagem acessível, que não podíamos nos basear em conhecimentos empíricos, crenças pessoais ou grupais (contexto cultural) quando o tema é a nossa saúde, mas sim no conhecimento científico, que muitas vezes se apóia nos conhecimentos populares na produção da promoção da saúde humana.

\section{DISCUSSÃO}

A primeira oficina do círculo de cultura foi um momento oportuno para identificarmos as palavras geradoras acerca do conceito de DT e não transmissível ditas pelos jovens. A literatura coloca as DT como patologias cujo agente etiológico é vivo e transmissível, podendo a infecção ser veiculada por um vetor, ambiente ou indivíduo ${ }^{1}$. Ainda na primeira oficina percebemos, no que diz respeito ao conceito de saúde, a predominância, entre os pesquisados, da concepção lógico-formal e comportamental, onde a saúde é compreendida, respectivamente, como ausência de doença e a harmonia do homem com a natureza e os outros indivíduos com os quais ele interage ${ }^{16}$.

No tocante à prática de exercícios, detectamos que os jovens avaliados têm consciência da importância da prática de atividades físicas e de lazer, porém, concordando com investigações realizadas entre adolescentes, notamos que em muitas ocasiões, a comunidade juvenil tem pouca opção para atividades físicas e/ou de lazer, o que a deixa na ociosidade que é preenchida, em casa ou na rua, com as drogas e marginalidade ${ }^{(17-18)}$.

$\mathrm{Na}$ vigência da segunda e terceira oficinas observamos que os adolescentes, em parte pela ação dos veículos de comunicação coletiva, detêm os conhecimentos acerca da prevenção de diversas DT, havendo poucas dúvidas no que toca as parasitoses e infecções como dengue e cólera, sendo os principais questionamentos oriundos da hanseníase, em parte, talvez, por não se apresentar consistentemente em sua cultura.

Em contrapartida, a quarta oficina, acerca das DST, foi a que mais entusiasmou os alunos e exigiu nosso desprendimento de conhecimento, já que até então a instituição de ensino não tivera abordado o conteúdo das DST. Os educadores da escola contemporânea precisam conhecer a preocupação dos adolescentes em relação ao corpo e à sexualidade aflorada, ajudando-os na vivência plena de sua sexualidade ${ }^{(17)}$.

Esta problemática, quanto à abordagem de conteúdos pedagógicos que explorem a sexualidade entre os jovens, é algo que, mesmo com a adoção de políticas publicas direcionadas, encontra-se freqüentemente nas escolas brasileiras. Os estudos propõem que a sexualidade dos adolescentes das séries iniciais tem ainda sido falada nas práticas didáticas pelos professores, por meio de práticas de ensino vinculadas ao discurso biológico e às construções das identidades sexuais e de gênero, limitando-se ao âmbito da instituição, esquecendo, assim, de que a verdadeira pedagogia orienta para a relação consigo, com os outros e com o mundo ${ }^{(19-20)}$.

Essa perspectiva que norteia o cenário escolar, por diversas vezes está associada à concepção do adolescente como uma figura imaculada ou assexuada, ou ainda, à crença de que a discussão desta temática estará despertando ou estimulando precocemente os adolescentes para a vivência de experiências sexuais. Assim fica claro que muitos educadores ainda vêem a sexualidade como ato sexual ${ }^{(19-20)}$.

Faz-se necessário, entre os educadores, compreender que o jovem com quinze a dezesseis anos de idade já tem sua sexualidade estruturada, visto que a vida adulta já está definida, podendo estar irredutível sua conduta ${ }^{4}$. Dessa forma, quanto mais precoce a Educação em Saúde sobre DST, como também DT, mais cedo o jovem será conscientizado dos métodos de prevenção dessas doenças.

\section{CONSIDERAÇÕES FINAIS}

As vivências desse estudo não esgotaram, mas reforçaram a visualização do círculo de cultura como uma estratégia de promover Educação em Saúde, pois, ao permitir a identificação do contexto cultural do grupo pesquisado, e, a partir dessa, o planejamento de métodos 
de intervenção adequados a realidade deles, acreditamos ter oferecido condições para a gênese de alterações de percepções diante da vulnerabilidade dos jovens em adquirir DT/DST. Acreditamos que uma vivência por um período superior ao que relatamos, certamente possibilitaria mudanças de comportamento efetiva nos jovens. Assim, ao final desse relato, nos ficam várias certezas: a primeira é que os jovens estão abertos para compartilhar e receber informações; a segunda, que o círculo de cultura pode ser um recurso de promoção da saúde frente às DT/DST, e a terceira a, mais importante, é que habita em cada um de nós, sujeitos desta sociedade, o instrumento para a produção da promoção da saúde humana: o querer mudar.

\section{REFERÊNCIAS}

1. Rouquayrol MZ, Façanha MC, Veras FMF. Aspectos Epidemiológicos das doenças transmissíveis. In: Rouquayrol MZ, Almeida Filho N. Epidemiologia \& saúde. 6a ed. Rio de Janeiro: MEDSI; 2003. p.229-31.

2. Laraia RB. Cultura: um conceito antropológico. 11a ed. Rio de Janeiro: Jorge Zahar; 1996. p.17-30.

3. Boletim Epidemiológico - Aids e DST. Ministério da Saúde/Secretaria de Assistência à Saúde. Brasília (DF): 2005; 1(26):30

4. Zagury T. O adolescente por ele mesmo. 11a ed. Rio de Janeiro: Record; 2000. p. 11-34.

5. Charbonneau PE. Adolescência e sexualidade. 6a ed. São Paulo: Paulinas; 1988. p.15-75.

6. Miranda MIF, Carvalho Ferriani MG. Políticas públicas sociais para crianças e adolescentes. Goiânia: AB; 2001. p.17-47.

7. Brasil. Ministério da Saúde - Secretaria executiva de DST/ AIDS. Políticas e diretrizes de prevenção das DST/AIDS entre mulheres. Ministério da Saúde; 2003. p.65-9.

8. Passetti E. Conversação libertária com Paulo Freire. São
Paulo, SP: Imaginário; 1998. p.34-55.

9. Souza M. Assistência de enfermagem em infectologia. São Paulo: Atheneu; 2000. p.290-5.

10. Manning PK, Cullum S. Betsy narrative, content and semiotic analysis. In: Denzin NK, Lincoln YS, editors . Handbook of qualitative research. Thousand Oaks: Sage; 1994.

11. Freire P. Educação como prática da liberdade. 23a ed. Rio de Janeiro: Paz e Terra; 1999. p.15-6.

12. Brandão CR. O que é método Paulo Freire. 25a ed. São Paulo: Brasiliense; 2004. p.11-32.

13. Freire P. Conscientização, teoria e prática da libertação: uma introdução ao pensamento de Paulo Freire. 3a ed. São Paulo: Moraes; 1980. p.28-94.

14. Cecagno D, Siqueira HCH, Cezar Vaz MR. Falando sobre pesquisa, educação e saúde na enfermagem. Rev Gaúch Enferm. 2005; 26(2): 154-60.

15. Silva YF, Franco MC, organizadores. Saúde e doença: uma abordagem cultural da enfermagem. Florianópolis: PapaLivro; 1996 . p.57.

16. Ramos FRS, Pereira SM, Rocha CRM. Viver e adolescer com qualidade. In: Associação Brasileira de Enfermagem. Adolescer: compreender, atuar, acolher. Brasília: ABEn; 2001. p.19-32.[Projeto Acolher].

17. Cardoso CP, Cocco MIM. Projeto de vida de um grupo de adolescentes à luz de Paulo Freire. Rev Latinoam Enfermagem. 2003; 11(6): 778-85.

18. Freudenberg N, Eng E, Flay B, Parcel G, Rogers T, Wallerstein N. Strengthening individual and community capacity to prevent disease and promote health: in search of relevant theories and principles. Health Educ Q. 1995; 22(3):290-306. Review.

19. Louro GL. Curiosidade, sexualidade e currículo. In: Louro GL, organizador. O corpo educado: pedagogias da sexualidade. Belo Horizonte: Autêntica; 1999. p.85-111.

20. Cano MAT, Ferriani MGC, Gomes R. Sexualidade na adolescência: um estudo bibliográfico. Rev Latinoam Enfermagem. 2000; 8(2): 18-24. 